\title{
Digital Civic Engagement in the EU: Analysing Examples, Tools, and Sentiment in Latvia and Estonia
}

\begin{abstract}
The decline of civic engagement has been an issue for several EU Member States. To promote civic engagement, digital tools have been perceived as one of the possible solutions both at the EU and national levels. Within the context of the COVID-19 pandemic that has intensified digitalisation in many forms and sectors, the issue of digital solutions for civic engagement has regained its relevance and topicality. In the last decade, Latvia has been among other EU Member States in which civic engagement has become a concerning and long-term challenge. For instance, as opposed to Estonia, voter turnout in the most recent national and European parliamentary elections has gradually declined in Latvia. There are also limited digital possibilities through which Latvian society can participate and influence the political agenda daily. Therefore, this article provides an overview of the provisions and guidelines at the EU level to address the issue of civic engagement by promoting digital democracy tools. Secondly, it analyses what digital tools exist in Latvia to promote civic engagement. Thirdly, by comparing the digital civic engagement solutions implemented in Estonia and Latvia, the lessons learned are drawn. Finally, using data from quantitative (polls) studies (before and during the COVID-19 pandemic), the article provides recommendations for Latvia in the context of I-voting.
\end{abstract}

Keywords: Civic Engagement, Latvia, I-voting, Digital Democracy

^ Martins Vargulis - Rīga Stradiṇs University, e-mail: martins.vargulis@rsu.lv, ORCID: 0000-0002-3969-0331. 


\section{Digital Civic Engagement: Theoretical Framework}

Civic engagement can be defined in many ways. Over recent decades, it has been used as a buzzword to cover everything from voting in elections to giving money to charity, or from bowling in leagues to participating in political rallies and marches. ${ }^{1}$ Various elements and aspects of civic engagement have been parts of diverse discussions in the academic field. One of the broadest definitions of civic engagement was once delivered by Robert D. Putnam, who argued that just about everything from reading newspapers, political participation, social networks, and interpersonal trust, to associational involvement - could all be labelled as forms of civic engagement. ${ }^{2}$ There have been scholars such as Ben Berger who have argued that civic engagement is ready for the dustbin - proposing that civic engagement meets a well-deserved end and be replaced with a more nuanced and descriptive set of engagements; the political, social, and moral. ${ }^{3}$ A broader description of civic engagement has been provided by $\mathrm{H}$. Brady who emphasises that we should think about political participation, firstly, as manifest and observable actions or activities that people voluntary take part in. Secondly, "people" should mean ordinary citizens, not political elites, or civil servants, and thirdly, according to the H. Brady, the concept refers to deliberate attempts to influence the people in power, to make a difference. ${ }^{4}$ Meanwhile, in their research, R. Adler and J. Goggin conclude that there is currently no single, widely agreed-upon meaning for the term..$^{5}$

When it comes to the term "digital civic engagement" things become even more complicated. The rise of the internet has stipulated civic engagement in various ways. Firstly, the internet as a tool for information retrieval, secondly, the internet as a tool for communicating and messaging, thirdly, the internet as a virtual space for exchanging views in forums,

${ }^{1}$ J. Ekman, E. Amna, Political Participation and Civic Engagement: Towards a New Typology, "Human Affairs" 2012, pp. 283-300, DOI: https://doi.org/10.2478/s13374012-0024-1.

2 R.D. Putnam, Bowling Alone: Democracy in America at Century's End, in: A. Hadenius, Democracy's Victory and Crises, Cambridge University Press, pp. 507-515, DOI: https://doi.org/10.1017/CBO9780511558832.003.

3 B. Berger, Political Theory, Political Science, and the End of Civic Engagement, "Perspectives on Politics", no. 7(2)/2009, pp. 335-350, DOI: https://doi.org/10.1017/ S153759270909080X.

4 J. Ekman, E. Amna, op.cit.

R.P. Adler, J. Goggin, What Do We Mean By Civic Engagement, "Journal of Transformative Education", no. 3(3)/2005, pp. 236-253, DOI: https://doi. org/10.1177/1541344605276792. 
surveys, comments, etc. Finally, the internet is a tool for a digital solution in policy-making procedures. One of the most comprehensive definitions of digital democracy has been provided by Ralf Lindner and Georg Aicholzer, who argue that digital democracy is the use of information and communication technology and computer-mediated communication in all kinds of media (e.g., the internet, interactive broadcasting, and digital telephony) for the purposes of enhancing political democracy or the participation of citizens in democratic communication. ${ }^{6}$

Regardless of the definition and tools, three main arguments have been put up supporting the notion of digital democracy: Digital democracy improves political information retrieval and exchange between governments, public administrations, representatives, political and community organisations, and individual citizens.

1. Digital democracy supports public debate, deliberation, and community formation.

2. Digital democracy enhances participation in political decision-making by citizens. ${ }^{7}$

As seen, the definition of digital civic engagement has been associated with various terms (e.g., eDemocracy, digital democracy, e-participation, I-voting, etc.). This research paper particularly analyses the perspective of the participation of society that is expressed through elections and its influence on decision making. Involving citizens as equal partners in decision-making processes contributes to successful democratic governance. In this context, digital tools provide the opportunity to ensure rapid and interactive cooperation between government and society, reduce the gap between political representatives and citizens, transform the relationship between citizens and decision-makers into more of a partnership as well as remove potential barriers to participation that translate into a general feeling of exclusion and engage under-represented groups.

I-voting is the most pronounced expression of digital civic engagement. In this article, I-voting is understood as an element of digital civic engagement, the use of digital technology in political and governance processes. It is not only a solution to make governance more efficient, but a tool to strengthen the democratic process. As is discussed later in this

6 R. Lindner, G. Aicholzer, E-Democracy: Conceptual Foundations and Recent Trends, in European E-Democracy, in: L. Hennen, Practice, Studies in Digital Politics and Governance, New York 2000 (Online publication date 31.12.2012), pp. 11-45, DOI: https://doi.org/10.4135/9781446218891.

7 J. van Dijk, Digital Democracy: Vision and Reality, in: Public Administration in the Information Age: Revisited, eds. I. Snellen, M. Thaens, W. van de Donk, Amsterdam 2012. 
article, I-voting isn't limited to Internet elections (municipal or parliament); it is a broader term that includes daily solutions provided by government and non-governmental organisations. Only by having a complex Internet solution would it increase overall digital civic engagement.

\section{Digital Democracy in the EU: Dynamics and Ambitions}

Over the last decade, the EU has sought to steer the debate on digital democracy with variable degrees of success. In the context of this discussion, there have been attempts to find both the right guidelines and the necessary tools to promote digital civic engagement. The European Commission is the main EU institution responsible for coordinating the implementation of digital democracy tools and guidelines. The implementation of digital democracy at the EU level must be seen in the context of one of the European Commission's priorities for 2019-2024, which is - Shaping Europe's digital future. As stated in the communication of Shaping Europe's digital future, promoting the digital transformation of public administrations across Europe is crucial. ${ }^{8}$

It should be noted that greater emphasis at the EU level is being placed on how digitalisation offers the opportunity to boost the economy in various areas, as well as to strengthen the resilience of the media and society. At the EU level, three eGovernment objectives have been set: 1) to modernise Public Administrations by using digital enablers, 2) to achieve cross-border mobility through interoperability, and 3) to facilitate digital interaction between administrations and citizens/businesses for high-quality public services. ${ }^{9}$ The EU's ambition in 2016 was that by 2020, public administrations and public institutions in the European Union should be open, efficient, and inclusive, providing borderless, personalised, user-friendly, end-to-end digital public services to all citizens and businesses in the EU. ${ }^{10}$ As can be seen, this goal has not been fully achieved. At the EU level, there is still considerable progress to be made with regard to proposing and implementing solutions to promote digital democracy daily.

8 Shaping Europe's Digital Future, European Commissions paper, https://ec.europa. eu/info/sites/default/files/communication-shaping-europes-digital-future-feb2020 en_4.pdf (access 17.05.2021).

9 EU eGovernment Report 2016, European Comission's report (2016), https:// digital-strategy.ec.europa.eu/en/news/eu-egovernment-report-2016-shows-onlinepublic-services-improved-unevenly (access 17.05.2021).

10 EU eGovernment Action Plan 2016-2020 Accelerating the digital transformation of government, $\operatorname{COM}(2016)$ 0179, Brussels (access 19.04.2016). 
The discussion on digital democracy has a long history. Several actors have been actively advocating the need for a more digitalised EU approach. Back in 2004, at the eDemocracy seminar, former Estonian Prime Minister Mart Laar suggested defining targets at the European level, for example, to use eParticipation to achieve increased interest and participation in the run-up to the European elections of 2009. According to Mart Laar, there is a need for further reflection and suggestions for shared initiatives and target-setting at the European level to give an impetus to the best use of ICT-driven innovation for improved democratic decisionmaking and participation. ${ }^{11}$ It was planned that innovative approaches would be used to design and deliver better services in line with the needs and demands of citizens and businesses as well as public administrations to use the opportunities offered by the new digital environment and to facilitate their interactions with stakeholders and with each other. ${ }^{12}$

With varying degrees of success, one digital solution is currently operating at the EU level. Originally known as "Your Voice in Europe", it is now offered as a single access point in all official languages for the Commission's public consultation. This is further enhanced by improved access to information about European institutions. It is within the context of a new generation of portals for a complete range of thematic information and interactive services on EU policies and activities, hiding its organisational complexity behind the scenes. The EU Presidencies have also become interested in making use of digital Democracy tools. One of the examples we can mention is eVote, a project started by the Greek presidency in $2003 .{ }^{13}$

\section{Civic Engagement in Estonia: Is I-voting a Solution?}

Challenges related to (insufficient) participation in political life are relevant to all Baltic states. The starting point for all the Baltic states in the further development of democracy was the same. Having said that, altogether the differences and similarities make the Baltic region an attractive area for the investigation of civic engagement and democratic values also in the context of global digitalisation stimulated by the COVID-19 pandemic.

11 P. Timmer, Agenda for eDemocracy - an EU perspective, European Commission, https://agora-parl.org/sites/default/files/agora-documents/EC\%20-\%20Agenda\%20 for\%20eDemocracy\%20-\%20EN\%20-\%20PI.pdf (access 21.08.2021).

12 EU eGovernment Action Plan 2016-2020, op. cit.

13 K. Carstens, Greeks reach out through e-Vote project, https://www.politico.eu/article/greeks-reach-out-through-e-vote-project/ (access 1.05.2021). 
Participation in elections is a key reference point for civic engagement. By comparing voter turnout in Estonia and Latvia since regaining independence, it is possible to observe fluctuations in both countries. As shown in Table nr.1, in general, turnout in Latvia has gradually decreased since regaining independence. In 1998, turnout in parliamentary elections was more than $70 \%$ of eligible citizens, compared to only $54 \%$ in the last parliamentary elections in 2018. The recession and non-involvement of society are a challenge to Latvia's democratic system. In Estonia, on the other hand, public involvement has remained steadily high. It has remained at $63-69 \%$ with slight fluctuations.

Table 1. Parliamentary election results in Estonia and Latvia - comparing participation

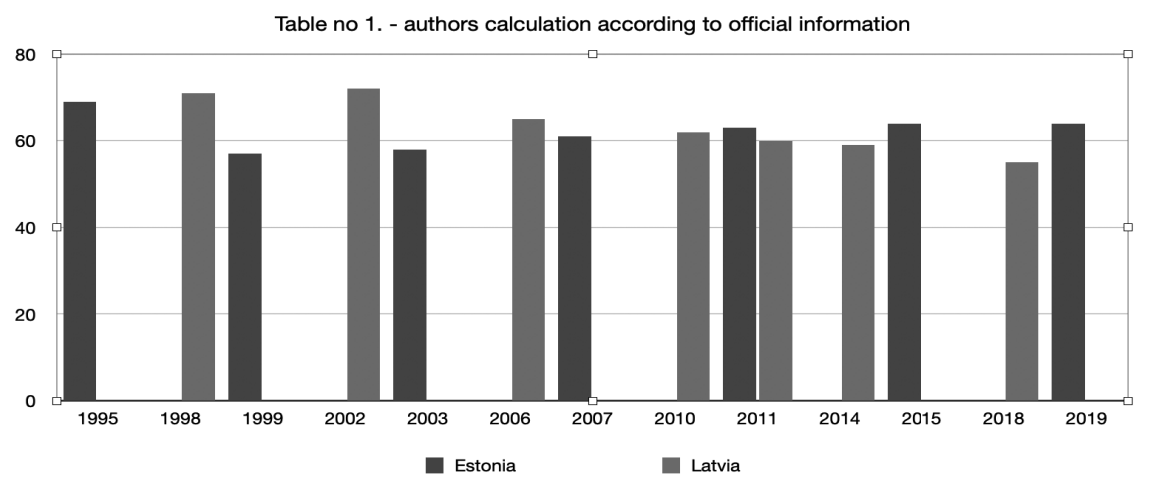

Source: made by author according to data published on the ACE Electoral Knowledge Network.

The turnout in the European Parliament elections is also higher in Estonia than in Latvia. Since 2004, when Estonia and Latvia joined the EU, four European Parliament elections have taken place. In the first three European elections in Estonia, turnout ranged from 43\% to 46\%. In 2019, it reached $51 \%$ of participation. In contrast, in the first two European Parliament elections in Latvia, there was $41 \%$ and $54 \%$ participation respectively. However, in 2014 and 2019, it was only $30 \%$ and $34 \%$ respectively, which is less than the EU average. It should be noted that in 2009, the comparatively high turnout in the European elections in Latvia can be explained by the fact that the European elections took place at the same time as the municipal elections. This also affected turnout in the European elections in general.

It should be also emphasised that since 2005, voter turnout in Estonia has increased, specifically when I-voting was introduced in the Estonian 
parliamentary elections. The share of I-voting has increased significantly since its introduction. In 2019, $43.75 \%$ of all votes were cast online, setting a record for I-voting. For comparison, the 2017 local elections posted a $31.7 \%$ I-voting share, while the 2015 parliamentary elections tallied $30.5 \%$ of ballots from I-votes; very different from the 2005 record of $1.9 \%$ I-voting turnout. ${ }^{14}$

Several studies have been conducted on whether and how I-voting has affected the participation of the Estonian public in elections. Overall, there is consensus among researchers that there is no measurement classifier to identify that I-voting has contributed to involving new voters in the elections. ${ }^{15}$ It is believed that I-voting is used by a widening range of the public; people who are an active part of society and who participated in elections even before 2005 when I-voting wasn't extant in Estonia.

This is related to the discussion that the use of I-voting cannot be seen from the perspective of rationality and maximum efficiency. Voters have different identities and rationale. Each voter has their reference points and preferences. Just because someone voted online doesn't automatically mean that they will vote online a second time. Also, many voters do not have access to remote electronic voting. Electronic voting could be a good substitute for offline alternatives for some people, but certainly not for everyone. As defined by Aaron Smith, the well-educated and the well-off are more likely than others to participate in civic engagement online just as those groups have always been more likely to be active in politics and community affairs offline. ${ }^{16}$ Political activity in social networking spaces shows a somewhat more moderate version of that trend. Therefore, it is impossible to identify specifically that remote electronic voting contributes to electoral activity.

${ }^{14}$ e-Estonia i-Voting - the Future of Elections?, https://e-estonia.com/i-voting-thefuture-of-elections/ (access 2.04.2021).

15 Including S. Karel, Remote Internet Voting: Happy Coincidence or Fact? The Case of Estonia, "Masaryk University Journal of Law and Technology", no. 9(2)/2015; $\mathrm{K}$. Vassil et al., The diffusion of internet voting. Usage patterns of internet voting in Estonia between 2005 and 2015, "Government Information Quarterly", no. 33(3)/2016, DOI: https://doi.org/10.1016/j.giq.2016.06.007; T. Unt, Does Internet voting make elections less social? Group voting patterns in Estonian e-voting log files (2013-2015), "PLOS ONE", no. 12(5)/2017, DOI: https://doi.org/10.1371/journal.pone.0177864 and T. Wigartz, Does Internet Voting in Estonia Affect Voter Turnout?, Master Thesis supervised by Annika Lindskog, Gothenburg 2017.

16 A. Smith, Civic Engagement in the Digital Age, Pew Research Center, https:// www.pewresearch.org/internet/2013/04/25/civic-engagement-in-the-digital-age/ (access 7.08.2021). 
It should be noted that the application of I-voting must be seen in the context of the overall digitalisation of Estonia at a national level. Over the last few decades, Estonia has been positioning itself and working to be seen as an e-country looking for various e-solutions in the public and private sectors. Estonia is also the only country in the world where local, national, and European elections take place in an e-environment. I-voting is not just one unique initiative that sets Estonia apart from other countries. Its citizens have been using internet banking since 1996, filing online tax returns since 2000, buying bus tickets with their mobile phones for a long time, and have been carrying out various other remote electronic transactions for many years that were not available in many parts of the world. What is also important was the introduction of the e-ID system, which allows for extensive activities in the daily environment, in business, and in correspondence with the public sector in the Internet environment. This has been an essential precondition for the public perception and application of online solutions.

Although the use of I-voting became more widespread in Estonia during the last elections (along with other e-solutions in private and public life), it should be noted that additional solutions within the context of civic engagement haven't been successfully implemented. One of the most significant, albeit temporary, tools of e-democracy that was introduced in Estonia was a platform named "Today I Decide". The platform was created in 2001. The aim of this project was the development of an electronic online participation system that enables citizens to submit ideas, discuss, and vote on them. The platform initially aroused public interest, but it did not gain widespread use. As a result, it was shut down in 2008.

As early as 2007, the government launched a new portal, Osalusveeb (meaning "the membership network"). The portal offers an opportunity to express an opinion on new laws and other legal acts prepared by the ministries, as well as an opportunity to vote on various ideas regarding public policy. However, this initiative has not received enough support from the public either. Every year, public involvement has diminished, which has fuelled discussions on closing the platform. ${ }^{17}$

Analysing the Estonia case, it can be concluded that I-voting has not given any impetus to the transformation of public culture and approach in favour of the use of digital tools in civic engagement. Although Estonia integrates digital solutions at the national level in various sectors and areas, this has not been reflected in the context of political participation

17 M. Toots, Why E-participation systems fail: The case of Estonia's Salee.ee, "Government Information Quarterly", no. 36(3)/2009, pp. 546-559, DOI: https://doi. org/10.1016/j.giq.2019.02.002. 
outside I-voting and the private sector. Moreover, government calls and initiatives for official opinions on certain bills are not widespread nor widely used by the public.

\section{Internet Participation in Latvia: The Success Story of ManaBalss.lv}

Comparing the examples of Latvia and Estonia, it must be concluded that Latvia lags behind Estonia in terms of electronic solutions in many forms of expression in daily life. E-identity is rooted in Estonia's culture in various areas and dimensions. However, there is currently one successful solution in Latvia in the context of civic engagement that works and is popular in society. Analysing Latvia's case, one separate online tool should be highlighted- the portal ManaBalss.lv (in English - My Voice). The portal ManaBalss.lv is a platform for public initiatives, where every Latvian citizen can place their initiative and collect signatures for its delivery to the Saeima (the Latvian Parliament). The portal works to make the most valuable ideas of the people heard. It is one of the largest and most successful grassroots participation projects in the history of Latvia, which has also been highly appreciated by leaders and organisations around the world.

At the heart of the action - legislative initiatives can be initiated and signed by any Latvian citizen who has reached the age of 16 . Any initiative that is signed online by at least 10,000 citizens and that meets the legal criteria of the parliament will be automatically sent to and afterwards considered by a specific committee of the parliament. The portal has become a recognisable and applicable tool. The statistics available on the portal's website show:

Table 2. Statistics of the submitted and signed initiatives through the ManaBalss platform

\begin{tabular}{|l|c|}
\hline Total number of signatures & $\mathbf{2 , 0 2 0 , 9 0 4}$ signatures \\
\hline Total number of initiatives submitted & 2030 initiatives \\
\hline Currently active published initiatives & 568 initiatives \\
\hline
\end{tabular}

Source: statistics drawn from manabalss.lv

Although the initiative has become a popular tool for public involvement in the legislative process, it is the only online platform that offers such solutions. 


\section{I-voting in Latvia: Analysing the Attitude of Latvian Society}

Although the ManaBalss.lv portal retains its relevance and application, an important issue is still related to the introduction of I-voting in Latvia. Analysing quantitative data surveys conducted before and during the COVID-19 pandemic, it is possible to conclude as to whether and how public sentiment regarding the introduction of I-voting has changed. The surveys also allow us to conclude the dynamics of development, as well as to analyse it from the perspective of counties, age, income, education, and employment.

Two quantitative surveys were conducted of Latvian residents aged 18 to 74 . Overall, 1000 respondents were questioned in both separate surveys. The stratified random sampling method according to the administrative-territorial principle was used to identify the respondents. Respondents were also divided into several classifiers: age, place of residence (region), level of education, state language as a colloquial language in the family, and other languages as a colloquial language in the family. Respondents were interviewed within one month and by one means of communication (either by telephone or in-person). The following three questions were asked during the survey: would you support the possibility to vote online in the Saeima, local government, European Parliament elections, and referendums in Latvia? what do you think would be the most important positive aspects of online elections? and what do you think would be the main negative aspects of online elections? Two surveys with identical questions and possible answers were conducted in 2019 and 2021 (February-March).

From the point of view of the public, it must be concluded that the public's perception of the introduction of I-voting at national and European parliamentary elections, as well as in referendums, has not increased in the face of COVID-19 challenges. Global digitalisation promoted by the COVID-19 pandemic has not given additional impetus to Latvian society. The total number of positive respondents ("yes" and "rather yes") is $63.9 \%$, which is $12.2 \%$ less than in the pre-COVID-19 pandemic times. Nevertheless, being aware of the potential risks, as well as the lack of information and discussion in the public discourse on I-voting, this indicator can still be classified as sufficiently high and positive. In general, it provides a basis for developing and improving the advancement of this issue in public discourse, as most of the society would be ready to support it.

It must be concluded that the diverse public attitude is not observed from the perspectives of education, nationality, or gender. Respondents 
in primary, secondary, and higher education have equal views on Internet solutions in the context of elections. There is also no significant change in dynamics before and under COVID-19 conditions. The situation is similar between women and men, as well as between Latvians and Russians. This survey also dispels the assumption that in an urban environment and the capital, the population is more focused on technological solutions. As the results of the survey prove, the support for I-voting is approximately similar in all regions of Latvia.

Analysing the arguments underpinning I-voting, both before and during the COVID-19 pandemic, the most important positive aspect of the introduction of I-voting is that it would provide more convenient voting (e.g., the possibility to vote regardless of location). This is the most positive aspect in all age groups, regardless of education or employment. It should also be emphasised that there is a degree of consensus between the public and private sectors. Neither during the COVID-19 pandemic nor before it has it been observed that any sector has been particularly critical of the introduction of I-voting. The percentage of support is very similar. It also leads to the conclusion that there is a consensus in both private and public sectors on the opportunities and the risks associated with the introduction of I-voting.

However, the synergy confirmed by both surveys is related to the impact of income on the perception of the introduction of I-voting. According to the survey findings, the higher the income, the greater the support for the introduction of I-voting. Given the digitalisation of the business environment, especially in the context of the COVID-19 pandemic, people on higher incomes are aware that this can be a solution in many ways, including in the context of public involvement.

Looking at the distribution by age groups, it should be noted that both before and during the pandemic, the 25-to-34 age group is the one that most positively evaluates the introduction of I-voting in Latvia. Before and during the COVID-19 pandemic, $82.3 \%$ and $75.8 \%$ of respondents in the 25-34 age group respectively, supported the introduction of I-voting. In turn, the most negative view of the introduction of I-voting in national and European parliamentary elections, as well as in referendums, is in the $65+$ age group. This group also shows the largest fluctuations before and during the COVID-19 pandemic. There is a significant drop in the support for I-voting. In the pre-COVID-19 pandemic, a total of $74 \%$ of respondents were positive about the introduction of I-voting. In the pandemic, however, it has decreased almost two fold. Respectively, $41.7 \%$ of respondents answered positively, of which only $20.3 \%$ answered "yes". The main reasons why this age group shies away from I-voting are, firstly, 
the falsification of results and, secondly, the disruption caused by cyberattacks and technical failures.

This shows that the older generation is more cautious about introducing technology into domestic and political life. Also, it is often the case that the information available in the public environment about several cyber-attacks discourages any showings of support for the implementation of I-voting. Taking this into consideration, under COVID-19, this age group has had to adapt to digitalisation, which may also have had the opposite effect, which is reflected in the mood towards the introduction of I-voting. The issue of the involvement of the elder generation has been expressed also in the resolution of the Council of Europe stating that an important challenge for e-democracy is to ensure an "equal hearing" of all groups. Efforts should be made to engage the elderly along with those less inclined to participate in politics, including youth. Since the Internet is a domain where younger generations tend to be well represented, re-engagement initiatives can help to mobilise them, which can, in turn, bring new energy to local and regional politics, which traditionally have lower levels of youth participation than national politics.

Analysing the risks identified by respondents as to why I-voting should not be introduced, disruption caused by cyber-attacks and technical failures comes to the fore. Almost $63 \%$ of respondents mention this as the most important criterion. It should be noted that this figure is lower than in the pre-COVID-19 survey when more than $75 \%$ of respondents highlighted this risk. This leads to the conclusion that the public is aware of the risks, but with the implementation of various tools and adaptation measures because of digitalisation, solutions are emerging to mitigate these attacks. This suggests that as society becomes more exposed to the various elements of digitalisation daily, risks will be identified, and tools put in place to reduce the level of threat and vulnerability. The possibility of a fairly high risk is also applied to the potential falsification of results, which is indicated by $43 \%$ of respondents.

\section{Conclusions}

Digital democracy in the EU is a developing trend. There are a set of goals defined at the highest levels aiming to promote the tools of digital democracy. However, when it comes to the implementation phase, both the EU and its Member States are still struggling to incorporate e-solutions in daily political life which would thereby increase civic engagement. Each country has its own solutions and tools. Having analysed the example of Estonia as a champion of implementing I-voting, it has been 
concluded that I-voting does not automatically give additional impetus for other online civic engagement solutions. Each of the digital democracy tools has its efficiency and support from the public. The support of society towards using them is interconnected with various variables, including the perception of the security risks that comes with online participation, the availability of remote systems, internet awareness, etc.

There is a particular online solution successfully operating in Latvia, which allows the initiating of legislation by every member of the public. It's been widely used by the public and has been an attractive platform in recent years. However, although it's been popular within society, it hasn't given additional impetus for other tools such as I-voting in national and European parliamentary elections. Analysing the attitude of Latvian society towards I-voting, several conclusions can be drawn. Firstly, there is very high support for introducing I-voting in national and European parliamentary elections. Secondly, the assumption that the digitalisation caused by the COVID-19 pandemic could increase overall public support for the use of online tools, including the introduction of I-voting, has not been confirmed. On the contrary; overall, it has even slightly decreased. There may be several reasons for this: a), with digitalisation in several everyday areas, the security risks it poses are being identified, and b), there is "fatigue" from the "overuse" of technology daily. Thirdly, it is important to emphasise that neither before nor during the COVID-19 pandemic, was there a significant split and difference of opinion depending on gender, education, and employment. The main difference is between the younger and older generation, where members of the public over the age of 65 are the most sceptical about the introduction of I-voting. Accordingly, it also serves as a basis for one of the recommendations - if the political elite would like to move forward with the introduction of I-voting in Latvia, then significant emphasis should be placed on explaining how to reduce security risks, what additional benefits I-voting brings, focussing specifically on the senior generation, which is typically one of the most active election groups in Latvia.

\section{Acknowledgments}

This publication has been prepared as a part of the Latvian State Research Program Project No. VPP-IZM-2018/1-0013 "Values in action: towards a responsible, secure and educated civic society with research and research models." 


\section{References}

Adler R.P., Goggin J., What Do We Mean By Civic Engagement, "Journal of Transformative Education", no. 3(3)/2005, DOI: https://doi. org/10.1177/1541344605276792.

Berger B., Political Theory, Political Science, and the End of Civic Engagement, "Perspectives on Politics", no. 7(2)/2009, DOI: https://doi.org/10.1017/ S153759270909080X.

Budge I. The New Challenge of Direct Democracy, Polity Press, Cambridge 1996.

Carstens K., Greeks reach out through e-Vote project, https://www.politico.eu/ article/greeks-reach-out-through-e-vote-project/ (access 1.05.2021).

van Dijk J., Digital Democracy: Vision and Reality, in: Public Administration in the Information Age: Revisited, eds. I. Snellen, M. Thaens, W. van de Donk, IOS Press, Amsterdam 2012.

e-Estonia i-Voting - the Future of Elections?, https://e-estonia.com/i-votingthe-future-of-elections/ (access 2.04.2021).

Ekman J., Amna E., Political Participation and Civic Engagement: Towards a New Typology, "Human Affairs" 2012, DOI: https://doi.org/10.2478/ s13374-012-0024-1.

EU eGovernment Action Plan 2016-2020 Accelerating the digital transformation of government, $\operatorname{COM}(2016)$ 0179, Brussels (access 19.04.2016).

EU eGovernment Report 2016, European Comission's report (2016), https://digital-strategy.ec.europa.eu/en/news/eu-egovernment-report-2016-shows-online-public-services-improved-unevenly (access 17.05.2021).

Hacker Kenneth L., van Dijk J., Digital Democracy: Issues of Theory and Practice, Sage, London 2000.

Lindner R., Aicholzer G., E-Democracy: Conceptual Foundations and Recent Trends, in European E-Democracy, in: L. Hennen, Practice, Studies in Digital Politics and Governance, Sage Publication, New York 2000 (Online publication date 31.12.2012), DOI: https://doi. org/10.4135/9781446218891.

Putnam R.D., Bowling Alone: Democracy in America at Century's End, in: A. Hadenius, Democracy's Victory and Crises, Cambridge University Press, Cambridge 1997, DOI: https://doi.org/10.1017/ CBO9780511558832.003.

Rabia Karakaya P., The Internet, and Political Participation, "European Journal of Communication", no. 20(4)/2005, DOI: https://doi. org/10.1177/0267323105058251. 
Karel S., Remote Internet Voting: Happy Coincidence or Fact? The Case of Estonia, "Masaryk University Journal of Law and Technology", no. $9(2) / 2015$.

Shaping Europe's Digital Future, European Commissions paper, https:// ec.europa.eu/info/sites/default/files/communication-shaping-europesdigital-future-feb2020_en_4.pdf (access 17.05.2021).

Smith A., Civic Engagement in the Digital Age, Pew Research Center, 2013, https://www.pewresearch.org/internet/2013/04/25/civic-engagementin-the-digital-age/ (access 7.08.2021)

Timmer P., Agenda for eDemocracy - an EU perspective, European Commission, https://agora-parl.org/sites/default/files/agora-documents/EC\%20 -\%20Agenda\%20for\%20eDemocracy\%20-\%20EN\%20-\%20PI.pdf (access 21.08.2021).

Toots M., Why E-participation systems fail: The case of Estonia's Salee.ee, "Government Information Quarterly", no. 36(3)/2009, DOI: https:// doi.org/10.1016/j.giq.2019.02.002.

Unt T., Solvak M., Vassil K., Does Internet voting make elections less social? Group voting patterns in Estonian e-voting log files (2013-2015), "PLOS ONE", no. 12(5)/2017, DOI: https://doi.org/10.1371/journal. pone. 0177864 .

Vassil K. et al., The diffusion of internet voting. Usage patterns of internet voting in Estonia between 2005 and 2015, "Government Information Quarterly”, no. 33(3)/2016, DOI: https://doi.org/10.1016/j.giq.2016.06.007.

Wigartz T., Does Internet Voting in Estonia Affect Voter Turnout?, Master Thesis supervised by Annika Lindskog, University of Gothenburg, Gothenburg 2017. 
